\title{
Generation of super-short avalanche electron beams in $\mathrm{SF}_{6}$
}

\author{
CHENG ZHANG, ${ }^{1,2}$ VICTOR F. TARASENKO, ${ }^{3,4}$ TAO SHAO,,${ }^{1,2}$ DMITRY V. BELOPLOTOV, ${ }^{3,4}$ \\ MIKHAIL I. LOMAEV, ${ }^{3,5}$ DMITRY A. SOROKIN, ${ }^{3}$ AND PING YAN ${ }^{1,2}$ \\ ${ }^{1}$ Institute of Electrical Engineering, Chinese Academy of Sciences, Beijing, China \\ ${ }^{2}$ Key Laboratory of Power Electronics and Electric Drive, Chinese Academy of Sciences, Beijing, China \\ ${ }^{3}$ Institute of High Current Electronics, Russian Academy of Sciences, Tomsk, Russia \\ ${ }^{4}$ National Research Tomsk State University, Tomsk, Russia \\ ${ }^{5}$ Tomsk State University of Control Systems and Radioelectronics, Tomsk, Russia \\ (RECEIVED 17 January 2014; ACCEPTED 19 February 2014)
}

\begin{abstract}
In this work, the generation of a super-short avalanche electron beam (SAEB) in $\mathrm{SF}_{6}$ in an inhomogeneous electric field is studied on two generators with pulse rise times of 0.5 and $2 \mathrm{~ns}$, respectively. The SAEB parameters in $\mathrm{SF}_{6}$ are compared with those obtained in other gases (air, nitrogen, argon, and krypton). It is shown that the SAEB amplitude in $\mathrm{SF}_{6}$ at pressures ranging from 0.05 to $0.2 \mathrm{MPa}$ is commensurable with that in krypton and is much lower than in air and nitrogen. It is also found that in $\mathrm{SF}_{6}, \mathrm{SF}_{6}$ mixture with $2.5 \%$ of nitrogen, and other gases, a diffuse discharge is ignited not only at negative polarity but also at positive polarity of the electrode with small curvature radius. Furthermore, the velocity of the ionization wave front in $\mathrm{SF}_{6}$ in an inhomogeneous electric field is studied. Experimental results show that the velocity of the ionization wave front in $\mathrm{SF}_{6}$ is lower than that in air and nitrogen as well as such velocity decreases when the pressure increases from 0.05 to $0.3 \mathrm{MPa}$ in all gases.
\end{abstract}

Keywords: Nanosecond pulse; Runaway electrons; Super-short avalanche electron beam; Velocity of the ionization wave front

\section{INTRODUCTION}

In recent years, there has been a lot of research progress achieved on generation of runaway electrons (RAEs) in laboratory gas discharges at increased pressure (see Levko et al., $2012 b$ ). Most attention in this field in the last decade was focused on the parameters and properties of RAEs in atmospheric air and on the mechanism of their generation. New experimental data were obtained due to the development of measuring equipment and technologies. The runaway electron beams downstream of a foil anode was proposed to term a super-short avalanche electron beam or shortly SAEB (Tarasenko et al., 2003). It is this term that we use throughout the paper.

Among the important results obtained since 2003, the most significant achievement is that the number of RAEs downstream of the anode measured in atmospheric air substantially increases. In the previous work (Tarasova et al., 1974), the number of RAEs was $10^{9}$, and subsequent works of other scientific groups failed to increase this

Address correspondence and reprint requests to: Tao Shao, Institute of Electrical Engineering, Chinese Academy of Sciences, PO Box 2703, 100190 Beijing, China. E-mail: st@mail.iee.ac.cn parameter (Babich, 2003; Babich \& Loiko, 2010). However, in 2003, about a 10-fold increase in the number of RAEs and amplitude of the beam current was observed by the Institute of High Current Electronics (IHCE) (Alekseev et al., 2003; Tarasenko et al., 2003). Note that the main data on the generation of RAEs and X-rays obtained until 2003 are reported (Babich, 2003), and analysis of various RAE measuring techniques, including those used by IHCE, is given elsewhere (Kostyrya et al., 2010; 2012; Tarasenko et al., 2007; 2008a; 2008b; 2008c; 2012b; Tarasenko, 2011).

The generation of SAEBs with maximum amplitudes requires numerous electron avalanches in the gap which, when overlapped, form a dense diffuse plasma. The front of this plasma crosses the gap with a high velocity from the cathode to the anode, generating a SAEB between the dense plasma front and the anode. In atmospheric air, the highest SAEB amplitude until now was obtained on the SLEP-150 generator (Tarasenko et al., 2011) and was about $100 \mathrm{~A}$ downstream of the $\mathrm{Al}$ foil anode (Kostyrya et al., 2012). The full width on the half maximum (FWHM) of the SAEB pulse (SAEB width) was about 100 ps and the number of RAEs in the beam was more than $6 \times 10^{10}$. Note that the SAEB amplitude and the number of 
RAEs mentioned above were not the limit and could be increased by decreasing the pulse rise time (Tarasova et al., 1974; Tarasenko et al., 2008c) as well as by optimizing the cathode material (Zhang et al., 2013) and cathode design (Kostyrya et al., 2010; 2012). The effect of the cathode material and design on the SAEB amplitude was also studied in other works (Tarasenko, 2011; Tarasenko et al., 2004; $2005 ; 2008 a ; 2008 c ; 2013 b)$. In nitrogen, hydrogen, and helium at decreased pressures, the SAEB amplitude from the entire anode foil on the SLEP-150 generator reached about 500 A with a FWHM of the beam current of about 100 ps (Tarasenko et al., 2010). Images of RAEs and/or $\mathrm{X}$-rays on films were obtained in nitrogen at a pressure up to $4 \mathrm{MPa}$ (Ivanov, 2013).

The SAEB width (about $100 \mathrm{ps)}$ that was actually measured in atmospheric air was first reported in the paper by Tarasenko et al. (2005). In later experiments, it was shown that the SAEB width depended on the anode diaphragm diameter, inter-electrode gap, kind of gas and gas pressure (Baksht et al., 2006; 2008; Kostyrya et al., 2012; Tarasenko, 2011; Tarasenko et al., 2008a; 2008b; 2010; $2012 a ; 2012 b)$. When the SAEB extracted from a diaphragm whose diameter was $1 \mathrm{~mm}$, SAEB pulses with a FWHM of about 25 ps were obtained (Tarasenko et al., 2012a; $2012 b$ ). However, the SAEB width from the entire anode foil surface in atmospheric air was about $100 \mathrm{ps.}$

With a tubular cathode, the SAEB in atmospheric air was generated into a solid angle larger than $2 \pi$ sr (Tarasenko et al., 2008a; 2008c), while with a grid cathode, the SAEB was detected in the direction opposite to the anode (Kostyrya et al., 2013). The X-ray exposure dose was $3 \mathrm{mR}$ per pulse (Kostyrya et al., 2013).

The generation of RAEs was observed at high pulse repetition frequencies. In atmospheric air, the $\mathrm{X}$-rays produced by RAEs in batches of 1500 pulses were detected at a frequency of up to $3 \mathrm{kHz}$ (Tarasenko, 2006). In the repetitive pulse mode, the $\mathrm{X}$-rays arose at a pulse repetition frequency of $1 \mathrm{kHz}$ (Shao et al., 2012a; Zhang et al., 2010). In the pulse repetitive mode at decreased pressures of nitrogen and helium, the SAEB was measured by a collector at a frequency of $1 \mathrm{kHz}$ (Erofeev et al., 2013). In atmospheric air, a dynamic capacitive current with amplitude of $4 \mathrm{kA}$ was measured as the ionization wave front propagated in the gap (Shao et al., 2013).

The generation of RAEs is a fundamental phenomenon in gas discharge physics. However, relevant papers, including those cited above, focus mostly on the generation of RAE beams in atmospheric air $(0.1 \mathrm{MPa})$ while the corresponding research on such generation in other gases is few. In particular, there are rather few data on the generation of RAE beams in $\mathrm{SF}_{6}$. Furthermore, sometimes these data are contradictory with each other.

The generation of SAEB in $\mathrm{SF}_{6}$ at atmospheric pressure was first reported by Babich and Loiko (1991). The number of RAEs in $\mathrm{SF}_{6}$ was judged from the blackening of $\mathrm{X}$-ray film and was estimated to be $10^{8}$ electrons per pulse, which was about 10 times lower than that in atmospheric air. The width of the beam current pulse was measured by using a scintillator and a photomultiplier at a time resolution of no longer than $3.5 \mathrm{~ns}$. The results that the RAE beam energy in $\mathrm{SF}_{6}$ was higher than that in air and that the beam generated in $\mathrm{SF}_{6}$ and air was mono-energetic with anomalous energy, in the authors' opinion (Babich \& Loiko, 1991), were apparently dubious due to measurement errors. The anomalous energy of RAEs was higher than $e U_{\mathrm{m}}$ (Babich \& Loiko, $1985 ; 1991$ ), and the $U_{\mathrm{m}}$ here referred to the maximum over-voltage in the discharge. This error of estimation of the electron energy in air (Babich \& Loiko, 1985) and $\mathrm{SF}_{6}$ (Babich \& Loiko, 1991) and/or voltage across the gap as well as incorrect description of the generation mechanism of RAE beams was repeated in publications of this scientific group, including in the monograph (Babich, 2003), within 20 years. However, as shown (Baksht et al., 2010; Tarasenko, 2011; Tarasenko et al., 2005; 2007; 2008a; 2008b; 2013b), the runaway electron beam downstream of the foil anode consisted of two or three groups of electrons of different energies and the number of electrons with anomalous energy was not more than 10\% (Baksht et al., 2010). No RAEs with anomalous energy in atmospheric air were detected, like in the study by Mesyats et al. (2011), and the energy of RAEs was assumed not to exceed $e U_{\mathrm{m}}$ under any conditions. All other things being equal, comparison of the energy of RAEs in $\mathrm{SF}_{6}$ and air demonstrated that the electron energy in air was higher than that in $\mathrm{SF}_{6}$, (Baksht et al., 2008).

A SAEB in $\mathrm{SF}_{6}$ at atmospheric pressure was measured for the first time with a collector at a sub-nanosecond time resolution (Baksht et al., 2006). It was shown that the FWHM of the beam current pulse in $\mathrm{SF}_{6}$ at a pressure of $0.1 \mathrm{MPa}$ was about 100 ps. In their work, the RADAN-220 generator (Zagulov et al., 1989) was used and the SAEB was obtained in six different gases, including gases of high atomic number $(\mathrm{Kr}$ and $\mathrm{Xe}$ ). However, no data were reported on the number of RAEs, SAEB amplitude, and the electron energy. The attempts to obtain a RAE beam in $\mathrm{SF}_{6}$ at a pressure of $0.1 \mathrm{MPa}$ (Mesyats et al., 2006) on the RADAN-303 generator (Yalandin \& Shpak, 2001) were unsuccessful, which was presumably due to the non-optimal design of the gas diodes and longer rise time of the voltage pulse. However, a RAE beam in air in this work was obtained. The most detailed study of the generation of RAEs in $\mathrm{SF}_{6}$ at high time resolution (up to $90 \mathrm{ps}$ ) was conducted elsewhere (Baksht et al., 2008). The SAEB was obtained at $\mathrm{SF}_{6}$ at pressures of up to $0.2 \mathrm{MPa}$ and it was shown that the SAEB pulse width depended on the pressure of $\mathrm{SF}_{6}$ and the amplitude of voltage pulse.

Note that there is another discrepancy in the research data on nanosecond-pulse discharges in $\mathrm{SF}_{6}$. According to the simulation results on the conductivity in $\mathrm{SF}_{6}$ and nitrogen where RAE was generated (Levko et al., 2012a) the plasma resistance within the first nanosecond after the breakdown in a $\mathrm{SF}_{6}$-filled gap at atmospheric pressure was two times lower than that in nitrogen. It was different from the experimental 
studies (Baksht et al., 2009; Tarasenko, 2001), which pointed out the plasma resistance at breakdowns in $\mathrm{SF}_{6}$ and $\mathrm{SF}_{6}$ -nitrogen mixtures was higher than that in nitrogen.

Taking into the consideration that the discharges in $\mathrm{SF}_{6}$ are not only for scientific interest, but has a great practical application value, because $\mathrm{SF}_{6}$ is widely used as an insulator in high-voltage devices (Bortnik, 1998) and also as one of the components in chemical gas lasers (Gross \& Bott, 1976), the present study continues the research (Baksht et al., 2006; 2008). The objective of the study is the characteristics of SAEB generation in $\mathrm{SF}_{6}$ and, for comparison, in air and other gases under the same experimental conditions. This paper also reports on the measurements of the ionization wave front velocity in the gap at a time resolution up to $10 \mathrm{ps}$.

\section{EXPERIMENTAL SETUP AND MEASUREMENT}

Experiments were performed on two setups at different voltage pulse rise times. Unlike the previous works, one of the setups (setup 1) was particularly designed for studying the discharges and RAE generation in $\mathrm{SF}_{6}$ and made it possible to measure several relevant parameters simultaneously. Thus, setup 1 allowed us to measure the voltage across the discharge gap, current through the gap, SAEB, and radiation from different gap regions in a single pulse. Moreover, the voltage pulse polarity of RADAN-220 generator in setup 1 could be both negative and positive.

The discharge chamber and measuring system are shown in Figure 1. The voltage pulse produced by the RADAN220 generator was applied through a short transmission line (5) to a tubular electrode with small curvature radius (7). This potential electrode (7) was made by rolling a $100-\mu \mathrm{m}$-thick stainless steel foil into a tube with a diameter of $6 \mathrm{~mm}$. The grounded plane electrode (9) was located at a distance of 8,10 , or $13 \mathrm{~mm}$ from the bottom surface of the potential electrode. The voltage was measured by a capacitive divider (6) located at the end of the transmission

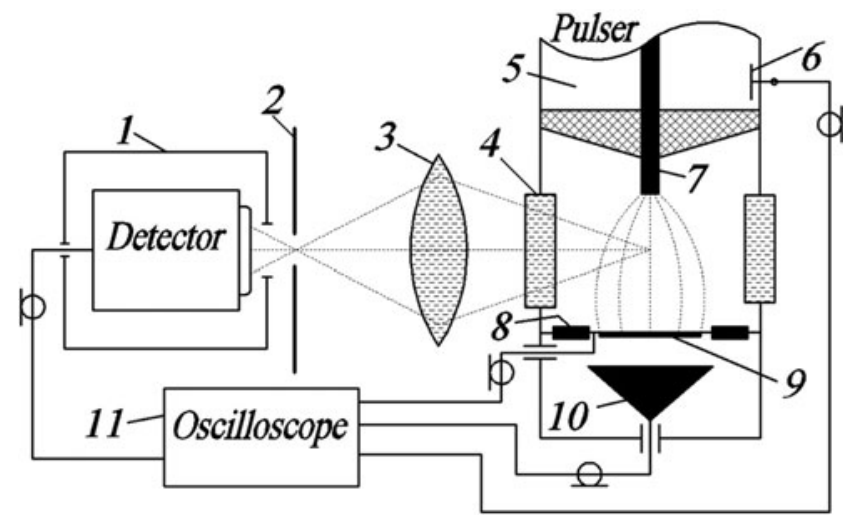

Fig. 1. Block-diagram of experimental setup 1: 1 = photodetector PD025 in metal box; $\mathbf{2}=$ screen with slit; $\mathbf{3}=$ lens; $\mathbf{4}=$ side window; $\mathbf{5}=$ transmission line of RADAN-220 generator; $\mathbf{6}=$ capacitive voltage divider; $7=$ high voltage electrode; $\mathbf{8}=$ current shunt; $\mathbf{9}=$ ground electrode made of thin foil; $\mathbf{1 0}=$ collector; $\mathbf{1 1}=$ oscilloscope . line (5). The generator was connected with the gap via the short transmission line (5) whose wave impedance was several times higher than that of the RADAN-220 generator, making it possible to increase the voltage pulse amplitude in the gap to about $340 \mathrm{kV}$. The voltage pulse duration at a matched load was about $2 \mathrm{~ns}$, and the pulse rise time in the transmission line was about $0.5 \mathrm{~ns}$. The discharge current was measured by a shunt (8) composed of chip resistors. The chip resistors were connected in series with the plane electrode (9) and were uniformly located at its circumference. The SAEB was measured by a collector (10) and was measured simultaneously with the discharge current and voltage pulse in the gap with negative polarity of the voltage pulse. For the measurement of SAEB in a gap of $13 \mathrm{~mm}$, the anode (9) was made of AlMg foil whose diameter was $1 \mathrm{~cm}$ and thickness was $50 \mu \mathrm{m}$ and was placed on a metal grid whose transparency was $14 \%$. The collector (10) was located downstream of the foil anode. For the measurement of SAEB in gaps of 8 and $10 \mathrm{~mm}$, the anode was made of either $40-\mu \mathrm{m}$-thick AlBe foil or $10-\mu \mathrm{m}$-thick $\mathrm{Al}$ foil, both with a diameter of $1 \mathrm{~cm}$. The anode from $\mathrm{Al}$ foil was placed on a metal grid whose transparency was $64 \%$. Note that the study was not aimed at measuring the current downstream of the entire anode surface with minimum beam current loss at the support grid and maximum SAEB amplitude. The discharge chamber was filled with $\mathrm{SF}_{6}, \mathrm{SF}_{6}$ mixture with $2.5 \%$ of nitrogen, air, argon, krypton, or nitrogen. Air, argon, krypton, and nitrogen were used in comparative experiments in order to estimate the number of electrons in the SAEB and investigate the mechanism of SAEB generation. The discharge chamber was pumped with a forevacuum pump. The pressures of gases ranged from 0.05 to $0.3 \mathrm{MPa}$.

The optical radiation from different discharge regions was extracted through a side window (4) and was transmitted by a lens (3) to a photodiode located in a metal box (1). Upstream of the photodiode, there was a shield (2) with a 1-mm-width slit. On the slit plane, a magnified image of part of the gap was formed; the magnification ratio was $2: 1$. When the plasma filled this region, the photodetector recorded the radiation from this region. The spatial resolution of the system for measuring the radiation from each region of the discharge gap was about $1 \mathrm{~mm}$ in the direction of the longitudinal gap axis. The radiation was measured in the regions near the cathode and anode. Signals from the capacitive voltage divider, shunt, collector, and photodiode were transmitted to a Tektronix DPO70604 oscilloscope $(6 \mathrm{GHz}, 25 \mathrm{GS} / \mathrm{s})$. The measuring elements were connected to the oscilloscope via RadioLab 5D-FB PEEG coaxial pulse cables with standard N-type connectors and Barth Electronics 142-NM attenuators with a bandwidth up to $30 \mathrm{GHz}$. Note that the SAEB parameters and spatial discharge images in air and nitrogen at negative polarity of voltage pulse were investigated in detail earlier (Baksht et al., 2010; Kostyrya et al., 2012; Shao et al., 2012; 2013; Tarasenko, 2011; Tarasenko et al., 2004; 2005; 2007; 2008a; 2008b; 2010; 2012a; 2012b; Zhang et al., 2010; 2013; see also Mesyats et al., 2006; 2011). 
For measuring the ionization wave velocity on setup 1, we also used a DSA 72504D oscilloscope (25 GHz, $100 \mathrm{GS} / \mathrm{s})$ and a PD025 high-speed photodetector (Photek) equipped with an LNS20 cathode, and the transient response rise time of the photodetector was about 80 ps. The relative timing jitter between light and voltage pulses was no longer than $10 \mathrm{ps}$. Integral radiation spectra were taken with an EPP-2000C spectrometer (Stellar-Net Inc.). Images of the discharge glow were taken with a Sony A100 reflex camera.

On setup 2, a VPG-30-200 generator with a longer rise time of the voltage pulse was used (Alekseev et al., 2013). The voltage acorss the discharge gap and the current through the gap or SAEB were measured simultaneously. The design of the VPG-30-200 generator is schematically shown in Figure 2. The main unit of the generator was an open-core resonance transformer (1) combined with a double coaxial forming line of wave impedance $60 \Omega$. The pulse transformer and generator circuit were similar in design to those used in the RADAN-303 generator (Yalandin \& Shpak, 2001). The switch (7) of the double forming line was formed by two spherical stainless steel electrodes. The switch case, the double coaxial forming line, and the transmission line were made of duralumin, and the insulator was made of kaprolon. The switch was filled with nitrogen at a pressure not more than $8 \mathrm{~atm}$. A breakdown of the switch generates a negative voltage pulse in the incident wave with amplitudes of $15-100 \mathrm{kV}$, a rise time of about $2 \mathrm{~ns}$, and a FWHM of about $4 \mathrm{~ns}$. The voltage pulse amplitude across the gas diode in the idle mode was varied from $30 \mathrm{kV}$ to $200 \mathrm{kV}$. The wave impedance of the transmission line was $65 \Omega$.

The cathode of the discharge gap (5) was a stainless steel tube whose inner diameter was $6 \mathrm{~mm}$ and edge thickness was about $100 \mu \mathrm{m}$. The plane anode through which the electron beam was extracted was made of $10-\mu \mathrm{m}$-thick $\mathrm{Al}$ foil. The electrode separation ranged from 4 to $20 \mathrm{~mm}$. In the transmission line, there were two capacitive dividers. One divider (2) was used to measure the rise time and the amplitude of the incident wave, and the other divider (3) was used to measure the voltage across the discharge gap of the gas diode (4).

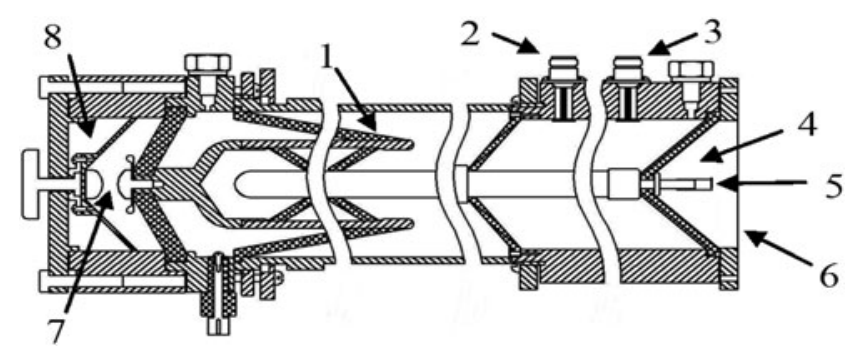

Fig. 2. Schematic of the VPG-30-200 generator. 1 = resonance transformer; $\mathbf{2}=$ capacitive divider located in the beginning of the generator transmission line at $20 \mathrm{~cm}$ from the gas diode anode; $\mathbf{3}=$ capacitive divider located at $9 \mathrm{~cm}$ from the gas diode anode; $\mathbf{4}=$ gas diode; $5=$ inter-electrode gap in the gas diode $d ; \mathbf{6}=$ anode foil; $7=$ inter-electrode gap in the generator switch; $\mathbf{8}=$ switch of the double forming line.
The discharge current was measured by a current shunt composed of chip resistors (size 1206). The net resistance of the shunt was $0.03 \Omega$. The number of runaway electrons in the beam downstream of the foil anode was measured by a collector with a receiving part diameter of $40 \mathrm{~mm}$. The time resolution of this collector was about $0.6 \mathrm{~ns}$. Signals from the collector, shunt, and dividers were recorded by a LeCroy WR204Xi oscilloscope (2 GHz, $10 \mathrm{GS} / \mathrm{s}$ ).

\section{EXPERIMENTAL RESULTS ON THE FIRST SETUP AND THEIR DISCUSSIONS}

On setup 1, we preliminarily studied the discharge images and the radiation spectra in the discharges in $\mathrm{SF}_{6}, \mathrm{SF}_{6}$ mixture with $2.5 \%$ of nitrogen, air, and nitrogen. Figures $3 \mathrm{a}, 3 \mathrm{c}, 3 \mathrm{~d}, 3 \mathrm{e}, 3 \mathrm{f}$ presents typical discharge images in $\mathrm{SF}_{6}$ for an inter-electrode gap of $13 \mathrm{~mm}$ at different pressures. For comparison, the discharge image in air at a pressure of $0.1 \mathrm{MPa}$ is shown in Figure $3 \mathrm{~b}$. In the case of negative polarity of voltage pulse, a diffuse discharge in $\mathrm{SF}_{6}$ was formed at pressures ranging from 0.05-0.2 MPa. Bright spots were only visible at the electrode with small curvature radius (tubular electrode). As the pressure increased to $0.25-0.3 \mathrm{MPa}$, a diffuse corona discharge was ignited. Compared with the diffuse discharge, not only bright spots appear at the tubular electrode, but also, brighter spark streamers (leaders) with small length were visible at the cathode with batches of 20 pulses. In

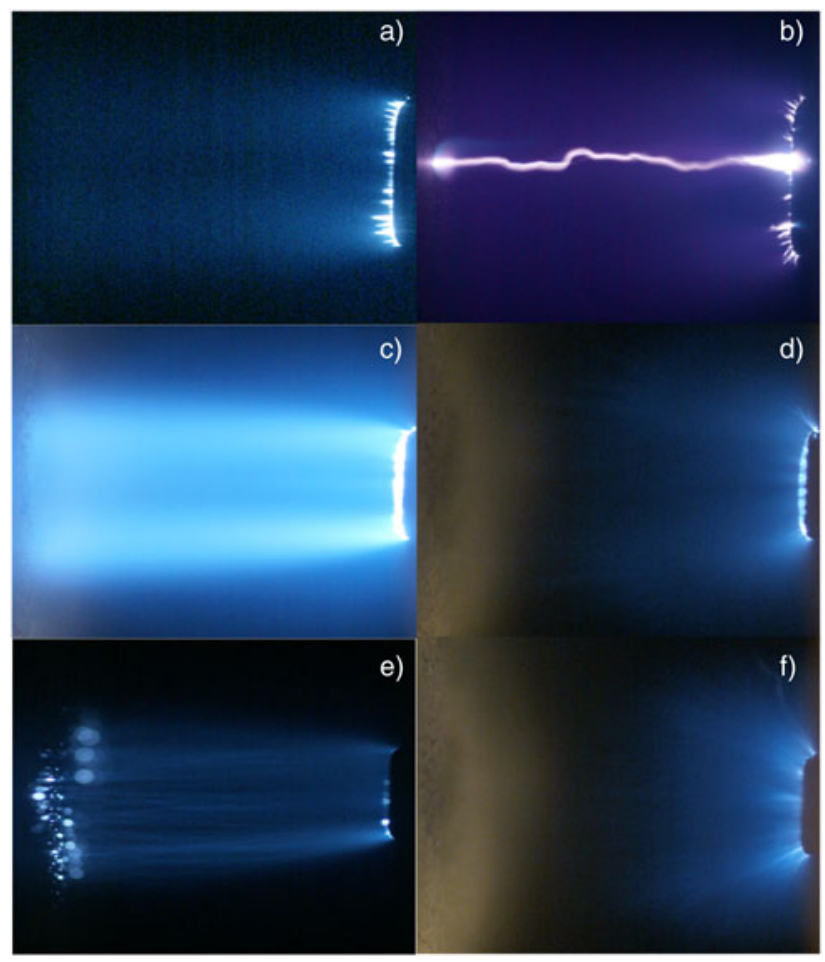

Fig. 3. (Color online) Discharge images with negative $(\mathbf{a}, \mathbf{b}, \mathbf{c}, \mathbf{d})$ and positive $(\mathbf{e}, \mathbf{f})$ polarity of RADAN-220 generator in of $\mathrm{SF}_{6}(\mathrm{a}, \mathrm{c}, \mathrm{d}, \mathrm{e}, \mathrm{f})$ and air (b) for one (a, b, e) and 20 (c, d, f) pulses. Pressures of gases 0.1 (a, b, e), 0.2 (c, f), and $0.25 \mathrm{MPa}(\mathrm{d})$. Tube electrode is from right side. $d=13 \mathrm{~mm}$. Cathode is on the right side of the photos. 
most of pulses, discharges formed in nitrogen under these conditions were also diffuse. However, all other things being equal, discharges in air at a pressure not more than $0.1 \mathrm{MPa}$, behaved a spark leader or spark channel in all cases (Fig. 3b).

In the case of positive polarity of voltage pulse, the discharge in $\mathrm{SF}_{6}$ was either a diffuse discharge or a diffuse corona discharge (Figs. 3e, 3f). However, bright spots appeared not only at the tubular electrode but also at the plane electrode (Fig. 3e). In most of pulses, the discharges at pressures of $0.05,0.1$, and $0.15 \mathrm{MPa}$ were all diffuse though they were less homogeneous than those in the case of negative polarity. The diffuse corona discharge was formed when the pressure exceeded 0.2 MPa (Fig. 3f). The formation of the diffuse discharge under the condition that the polarity of the electrode with small curvature radius was positive proved the fallacy that diffuse discharges were formed due to monoenergetic electrons with anomalous energy generated at the front of a polarized streamer near the cathode (Babich \& Loiko, 1991; Babich, 2003). Our studies showed that bright spots at the plane cathode arose after the formation of a diffuse discharge in the gap under this condition.

When an inter-electrode gap was $13 \mathrm{~mm}$, diffuse discharges were obtained in $\mathrm{SF}_{6}$ mixture with $2.5 \%$ of nitrogen, air, argon, krypton, and nitrogen. As the inter-electrode gap and the gas pressure decreased, the transition from diffuse discharge to spark discharge was observed. Actually, it was the diffuse corona discharge that first arose, then a diffuse discharge. Only thereafter did the spark leaders cross the interelectrode gap, resulting in the generation of a spark (see also Shao et al., 2012b).

As shown by spectral analysis, the major contribution to the radiation from the gap in a diffuse discharge was from bands of the second positive nitrogen system. Its radiation was detected by the photodetector in $\mathrm{SF}_{6}$-nitrogen mixture, air, and nitrogen at all pressures. $\mathrm{In}^{\mathrm{SF}_{6}}$ at decreased pressures, radiation of the second positive nitrogen system was also detected. This radiation was due to the presence of small amount of nitrogen in $\mathrm{SF}_{6}$ (less than $0.5 \%$ ). However, the radiation intensity of the second positive nitrogen system in $\mathrm{SF}_{6}$ was much lower than that in nitrogen, air, and $\mathrm{SF}_{6}$ mixture with $2.5 \%$ of nitrogen. In this paper, in order to investigate the radiation from different gap regions, we used a mixture of $\mathrm{SF}_{6}$ with $2.5 \%$ of nitrogen, because in this mixture, the breakdown voltage of the gap was almost constant and the radiation intensity of the second positive nitrogen system increased an order of magnitude, making it possible to record the time at which radiation arose in different gap regions at all pressures.

It was reported that bright spots at the electrode with small curvature radius appeared in less than $1 \mathrm{~ns}$ (Baksht et al., 2009), but their radiation intensity within the first nanoseconds was small. Scanning the spectrum ranged from 200 to $800 \mathrm{~nm}$ in the spark discharge, broadband radiation was observed with superimposed radiation of different narrow bands that were not identified in the work. Note that similar radiation spectra in $\mathrm{SF}_{6}$ were obtained even earlier (Baksht et al., 2008).
Waveforms of the voltage discharge current, and radiation from different gap regions were taken at both polarities of RADAN-220 generator at pressures ranged from 0.05 to $0.3 \mathrm{MPa}$. A SAEB was detected in most cases at negative polarity of the generator. Figure 4 shows waveforms of the voltage, discharge current, $\mathrm{SAEB}$, and radiation in $\mathrm{SF}_{6}$ at a

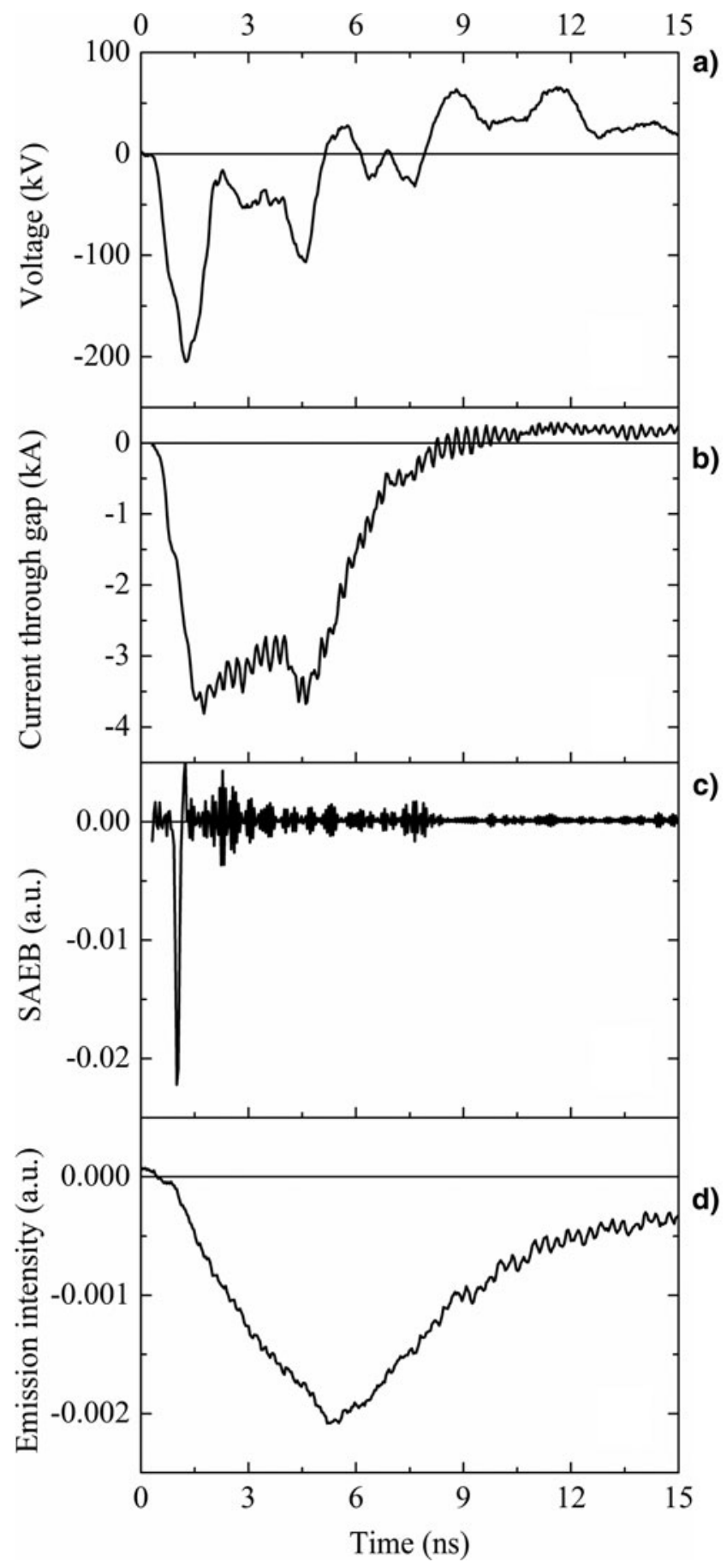

Fig. 4. Waveforms of voltage pulses (a), current through gap (b), runaway electron beam behind foil (SAEB) (c), and emission intensity (d) near tube electrode with negative polarity of RADAN-220 generator, $d=13 \mathrm{~mm}$. Pressure of $\mathrm{SF}_{6}$ : $0.05 \mathrm{MPa}$. 
pressure of $0.05 \mathrm{MPa}$ from the region near the electrode with small curvature radius. The waveforms were the average for approximately 30 pulses. All waveforms were synchronized in time with an accuracy of no longer than $0.2 \mathrm{~ns}$, and their relative timing jitter with the DPO70604 oscilloscope was no longer than $40 \mathrm{ps}$. It was seen that the radiation from the discharge region arose during the rise time of the voltage pulse. For negative polarity, the SAEB was detected during the rise time of both the voltage pulse and discharge current. Similar sets of waveforms were obtained in $\mathrm{SF}_{6}$ at other different pressures as well as in other gases and gas mixtures. The inter-electrode gaps in these experiments were 13, 10, and $8 \mathrm{~mm}$. However, in $\mathrm{SF}_{6}$, for both negative polarity with higher pressures and positive polarity for all gases, the SAEB could not be detected. All other things being equal, the highest SAEB amplitudes were obtained in nitrogen and air among next the gases: $\mathrm{SF}_{6}$, air, nitrogen, argon, and krypton.

Through measuring the radiation from near-electrode regions of the gap, we observed that the radiation first arose at the electrode with small curvature radius and then at the plane electrode. Figure 5 shows waveforms of the radiation from the near-cathode (1) and near-anode regions (2) in $\mathrm{SF}_{6}$ mixture with $2.5 \%$ nitrogen at a pressure of $0.2 \mathrm{MPa}$ when the polarity of the voltage pulse was negative. The data were obtained with the DSA 72504D oscilloscope with the relative timing jitter between light and voltage pulses of no longer than $10 \mathrm{ps}$. It was seen that the radiation pulse from the near-anode region appeared later than that from the near-cathode region. Such delay was due to the formation of an ionization wave whose front moved from the electrode with small curvature radius to the plane electrode. The passage of the ionization wave corresponded to the onset of efficient excitation and ionization in the gap. The ionization wave front velocity could be determined from the corresponding data, $2 \%$ of the peaks of emission

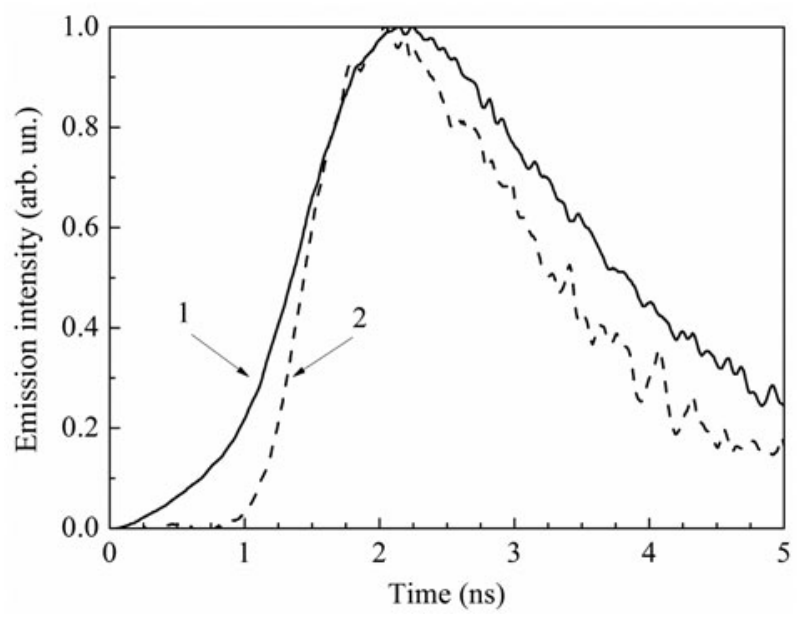

Fig. 5. Waveforms of emission intensity near cathode (1) and plane anode (2) in $\mathrm{SF}_{6}$ with $2.5 \%$ nitrogen at $0.2 \mathrm{MPa}$ pressure. Negative polarity of RADAN-220 generator, $d=13 \mathrm{~mm}$. intensities in the initial portions of waveforms of the radiation from different gap regions. The signal to noise ratio was $\geq 2$. The measurements showed that in the $\mathrm{SF}_{6}$ mixture with $2.5 \%$ nitrogen, the delays of radiation from the nearanode region were longer than those in air and nitrogen. Furthermore, these delays increased with the gas pressure, and their values in $\mathrm{SF}_{6}$ and nitrogen at a pressure of $0.2 \mathrm{MPa}$ were 0.7 and $0.26 \mathrm{~ns}$, respectively. The radiation from the gap arose almost simultaneously at all pressures of the gases. Therefore, the delay of ionization processes corresponded to the onset of voltage rise in the gap did not completely depend on pressure, but depended on electric field amplification on micro- and macro-protrusions at the electrode with small curvature radius. Similar radiation dynamics were observed when positive voltage pulses applied to the potential electrode, but the delay in this case was shorter.

Figure 6 shows waveforms of the voltage in $\mathrm{SF}_{6}$ and air at different pressures with an inter-electrode gap of $8 \mathrm{~mm}$. The corresponding waveforms of the SAEB in $\mathrm{SF}_{6}$ and air are presented in Figure 7. In the case of the RADAN-220 generator with a gap of 13 and $8 \mathrm{~mm}$, the side walls of the gas diode were not covered with an insulator (Fig. 1). When the gap decreased from 13 to $8 \mathrm{~mm}$, the SAEB amplitude in $\mathrm{SF}_{6}$ was increased and the RAE beam was obtained at a pressure of $0.2 \mathrm{MPa}$ in $\mathrm{SF}_{6}$. The use of the insulator covering the side walls of the gas diode made it possible to obtain a SAEB with an inter-electrode gap of $10 \mathrm{~mm}$ at a pressure of $0.2 \mathrm{MPa}$ in $\mathrm{SF}_{6}$. Comparison of the SAEB amplitudes in $\mathrm{SF}_{6}$, air, and nitrogen showed that under the same conditions, the SAEB amplitude in air and nitrogen was at least ten times higher than that in $\mathrm{SF}_{6}$ (see Table 1 and Fig. 7). This result was consistent with the data obtained earlier (Babich \& Loiko, 1991; Baksht et al., 2008). In addition, all other

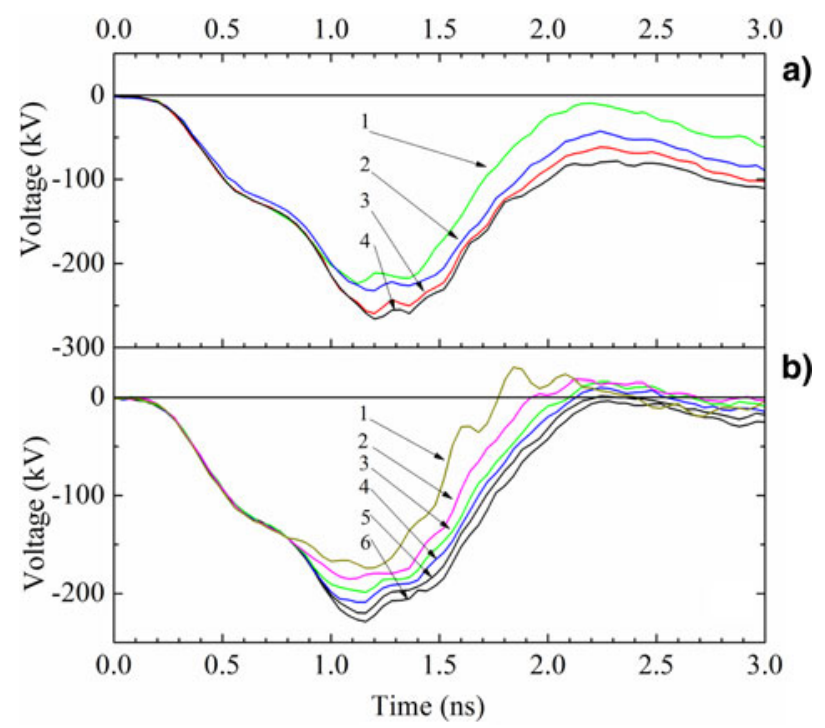

Fig. 6. (Color online) Waveforms of voltage pulses in $\mathrm{SF}_{6}(\mathbf{a})$ and air (b) at different pressures. Negative polarity of RADAN-220 generator, $d=8 \mathrm{~mm}$. (a) Pressures: 1-0.1, 2-0.15, 3-0.18, 4-0.2 MPa. (b) Pressures: 1-0.05, 2-0.1, 3-0.15, 4-0.2, 5-0.25, 6-0.3 MPa. 

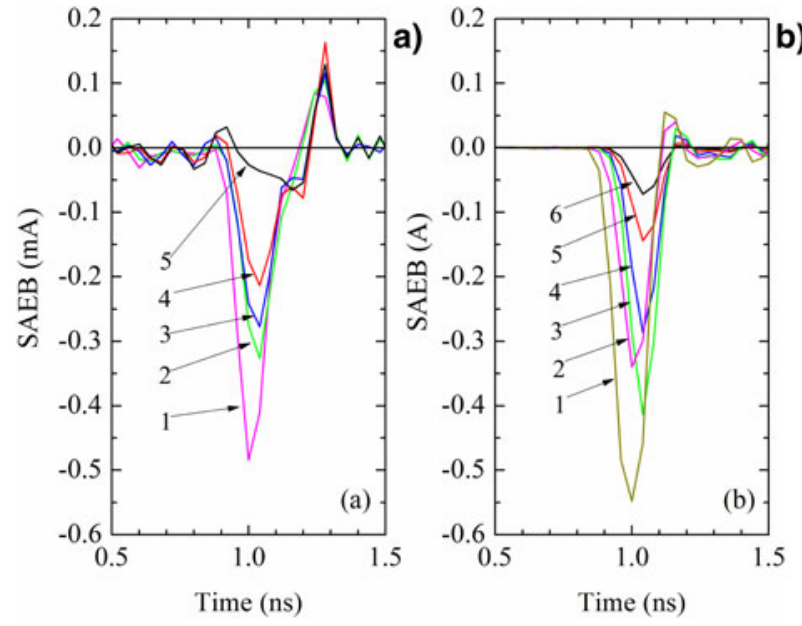

Fig. 7. (Color online) Waveforms of SAEB pulses in $\mathrm{SF}_{6}$ (a) and air (b) at different pressures. Negative polarity of RADAN-220 generator. (a) Pressures: $1-0.1,2-0.12,3-0.15,4-0.18,5-0.2 \mathrm{MPa}$. (b) Pressures: 1-0.05, $2-0.1,3-0.15,4-0.2,5-0.25,6-0.3 \mathrm{MPa} . d=8 \mathrm{~mm}$.

things being equal, the FWHM of the SAEB pulse in $\mathrm{SF}_{6}$ were $15 \%$ higher than that in air.

The SAEB amplitudes in air and nitrogen under the same conditions differed little. The SAEB amplitude in krypton at atmospheric pressure was 10 times lower than that in nitrogen and air but was little different from that in $\mathrm{SF}_{6}$. The SAEB amplitude in argon at atmospheric pressure was lower than that in nitrogen and air but much higher than that in krypton. From this comparison, it was obvious that the SAEB amplitude was more influenced by the atomic weight of a gas, more precisely, the electron energy lost in ionization and excitation, rather than by its electronegative properties.

Figure 8 shows experimental the dependence of SAEB attenuation on the thickness of the foils. These attenuation curves were calculated by the procedure described in the paper (Baksht et al., 2010) and used to reconstruct RAE beam spectra. The RAE beam spectra reconstructed by this procedure for $\mathrm{SF}_{6}$ and air are shown in Figure 9. It was seen that the electron energy corresponding to the peak of the electron energy distribution in air was higher than that in $\mathrm{SF}_{6}$, though the maximum voltages across the gap in

Table 1. Average $S A E B$ amplitude (for 30 pulses) in $S_{6}$ and air. Negative polarity of RADAN-220 generator, $d=8 \mathrm{~mm}$

\begin{tabular}{lcl}
\hline \hline & $\mathrm{SF}_{6} ; i_{\mathrm{e}-\mathrm{b}}, \mathrm{mA}$ & Air; $i_{\mathrm{e}-\mathrm{b}}, \mathrm{mA}$ \\
\hline$p=0.05 \mathrm{MPa}$ & $\mathrm{n} / \mathrm{m}$ & \\
$p=0.1 \mathrm{MPa}$ & 0.48 & 540 \\
$p=0.12 \mathrm{MPa}$ & 0.33 & $\mathrm{n} / \mathrm{m}$ \\
$p=0.15 \mathrm{MPa}$ & 0.28 & 410 \\
$p=0.18 \mathrm{MPa}$ & 0.21 & $\mathrm{n} / \mathrm{m}$ \\
$p=0.2 \mathrm{MPa}$ & 0.05 & 280 \\
$p=0.25 \mathrm{MPa}$ & - & 140 \\
$p=0.3 \mathrm{MPa}$ & - & 70 \\
\hline \hline
\end{tabular}

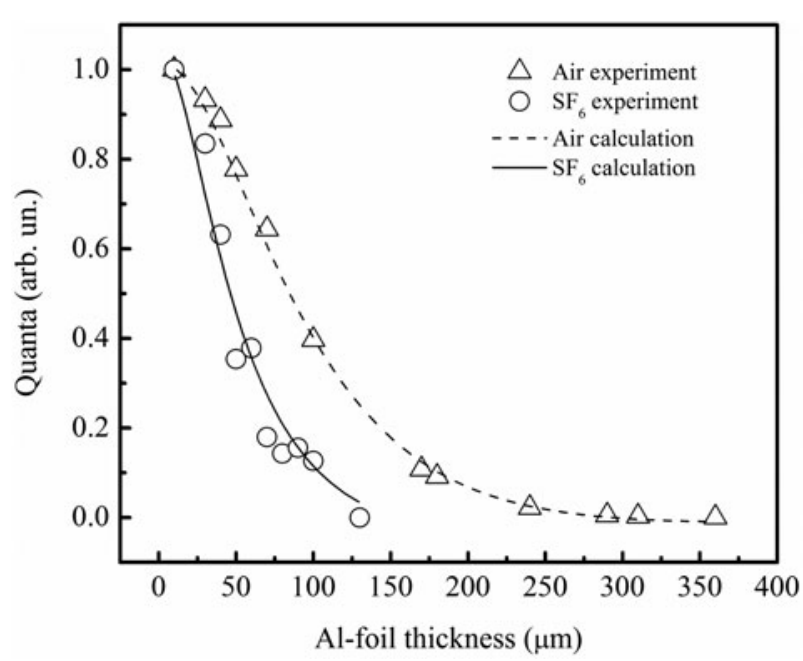

Fig. 8. Attenuation curves for the electron beams generated in $\mathrm{SF}_{6}$ and air at pressure $0.1 \mathrm{MPa}$. Negative polarity of RADAN-220 generator, $d=10 \mathrm{~mm}$.

$\mathrm{SF}_{6}$ under similar conditions were somewhat higher than that in air and nitrogen (Table 2). The breakdown voltages in air and nitrogen under these conditions differ little, and increased with the pressure for all three gases. It should be pointed out that, in the spectra shown in Figure 9, only the main group of RAEs could be seen. The second group of electrons with energies less than $50 \mathrm{keV}$, which were detected in atmospheric air (Baksht et al., 2010; Tarasenko et al., 2005), was absent in these spectra, because these electrons were cut-off by the foil anode.

Waveforms of the current and voltage for $\mathrm{SF}_{6}$ and nitrogen at a pressure of 0.1 MPa are shown in Figure 10. All other things being equal, the discharge current for nitrogen was higher than that for $\mathrm{SF}_{6}$ while the maximum voltage for nitrogen was lower than that for $\mathrm{SF}_{6}$. However, these experimental data on conductivity in $\mathrm{SF}_{6}$ and nitrogen were inconsistent with the calculation results that the resistance in $\mathrm{SF}_{6}$ in the

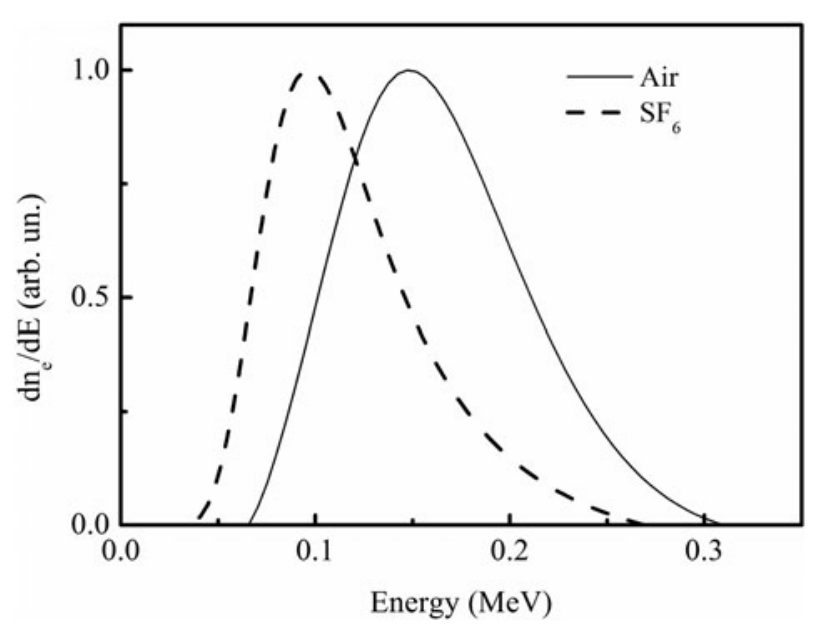

Fig. 9. Reconstructed spectrum of $\mathrm{SAEB}$ in $\mathrm{SF}_{6}$ and air at pressure $0.1 \mathrm{MPa}$. Negative polarity of RADAN-220 generator, $d=10 \mathrm{~mm}$. 
Table 2. The maximum voltages on the gap at different pressures of $S F_{6}$, air and nitrogen and different gap spacing. Negative polarity of RADAN-220 generator

\begin{tabular}{llll}
\hline \hline & $\mathrm{SF}_{6} ; U_{\mathrm{m}}, \mathrm{kV}$ & Air; $U_{\mathrm{m}}, \mathrm{kV}$ & $N_{2} ; U_{\mathrm{m}}, \mathrm{kV}$ \\
\hline$d=8 \mathrm{~mm}, p=0.1 \mathrm{MPa}$ & 224 & 185 & $\mathrm{n} / \mathrm{m}$ \\
$d=13 \mathrm{~mm}, p=0.1 \mathrm{MPa}$ & 242 & 208 & 229 \\
$d=8 \mathrm{~mm}, p=0.2 \mathrm{MPa}$ & 266 & 220 & $\mathrm{n} / \mathrm{m}$ \\
$d=13 \mathrm{~mm}, p=0.2 \mathrm{MPa}$ & 314 & 234 & 239 \\
\hline \hline
\end{tabular}

first nanosecond was two times lower than that in nitrogen and the amplitude of dynamic capacitive current for $\mathrm{SF}_{6}$ was also lower than that for nitrogen (Levko et al., 2012a). Actually, the dynamic capacitive current arose between the dense plasma front and the anode (Shao et al., 2013). In our opinion, it was mainly due to the lower velocity of the ionization wave front from the cathode to the plane anode in heavy electronegative gas $\left(\mathrm{SF}_{6}\right)$. Furthermore, once the ionization wave front crossed the gap, the conduction current in $\mathrm{SF}_{6}$ was lower than that in nitrogen. Our measurements of the current through the gap confirmed the previous experimental data (Baksht et al., 2008; 2009; Tarasenko, 2001). The plasma resistance in $\mathrm{SF}_{6}$ and in $\mathrm{SF}_{6}$-nitrogen mixture was higher than that in nitrogen under the same conditions.

\section{EXPERIMENTAL RESULTS ON THE SECOND SETUP AND THEIR DISCUSSION}

Figure 11 shows oscillograms of the voltage across the gap, discharge current, and SAEB at the rise time of the voltage

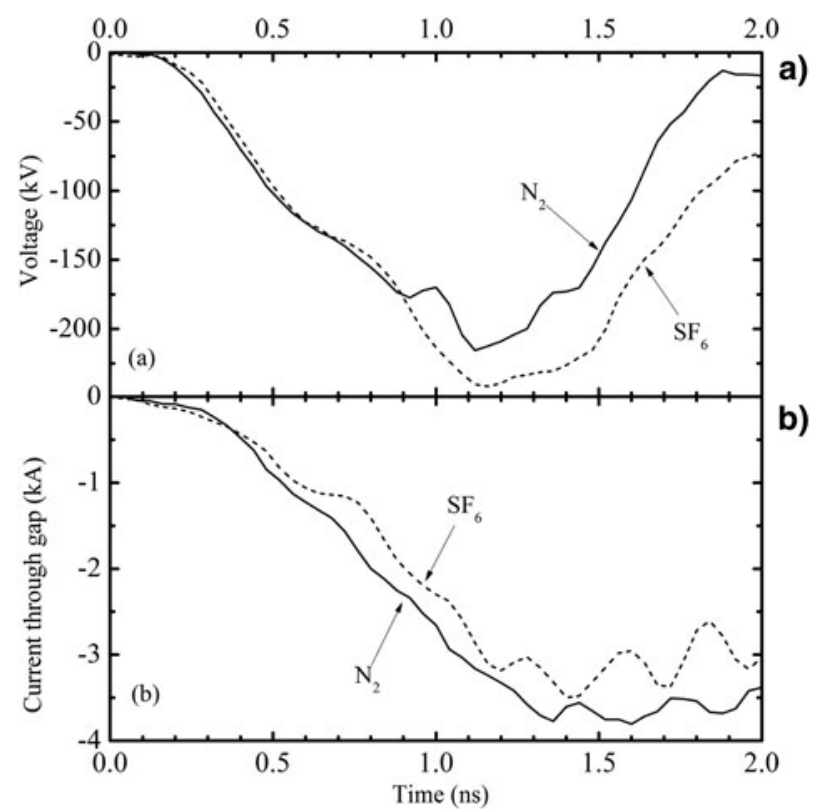

Fig. 10. Waveforms of voltage pulses (a) and current through gap (b) in $\mathrm{SF}_{6}$ and nitrogen at pressure $0.1 \mathrm{MPa}$. Negative polarity of RADAN-220 generator, $d=13 \mathrm{~mm}$.

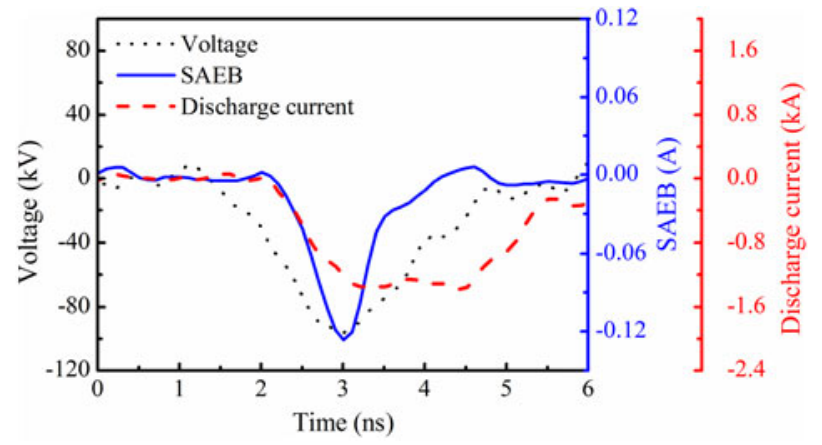

Fig. 11. (Color online) Waveforms of voltage pulse, discharge current and SAEB behind foil at pressures of $\mathrm{SF}_{6} 200 \mathrm{~Pa}$. VPG-30-200 generator, $d=$ $12 \mathrm{~mm}$.

pulse of about $2 \mathrm{~ns}$. On the setup 2, the time resolution of the measuring system was about $0.5 \mathrm{~ns}$, which was sufficient to record voltage pulses without any strong distortion and to measure the FWHM of the SAEB at low pressures in $\mathrm{SF}_{6}$ when the discharge transited to the "vacuum diode" mode (Tarasenko et al., 2010). Waveforms of the voltage across the gap for $\mathrm{SF}_{6}$ at different pressures are shown in Figure 12a, and waveforms of the beam current are presented in Figure $12 \mathrm{~b}$. Increasing the rise time of voltage pulse to about $2 \mathrm{~ns}$ could lead to a substantial decrease of SAEB current amplitude for $\mathrm{SF}_{6}$ at pressures higher than $200 \mathrm{~Pa}$ (Fig. 13). The SAEB amplitude decreased for both interelectrode gaps (12 and $8 \mathrm{~mm}$ ), and it was higher for the gap of $8 \mathrm{~mm}$ than that for the gap of $12 \mathrm{~mm}$. At the pressure of $0.1 \mathrm{MPa}$, the SAEB amplitude for $\mathrm{SF}_{6}$ was more than an order of magnitude lower than that of air, further supporting the results obtained on setup 1 . In addition, the increase of the FWHM of the beam current pulse at low pressures was related to the transition of the discharge to the vacuum diode mode.

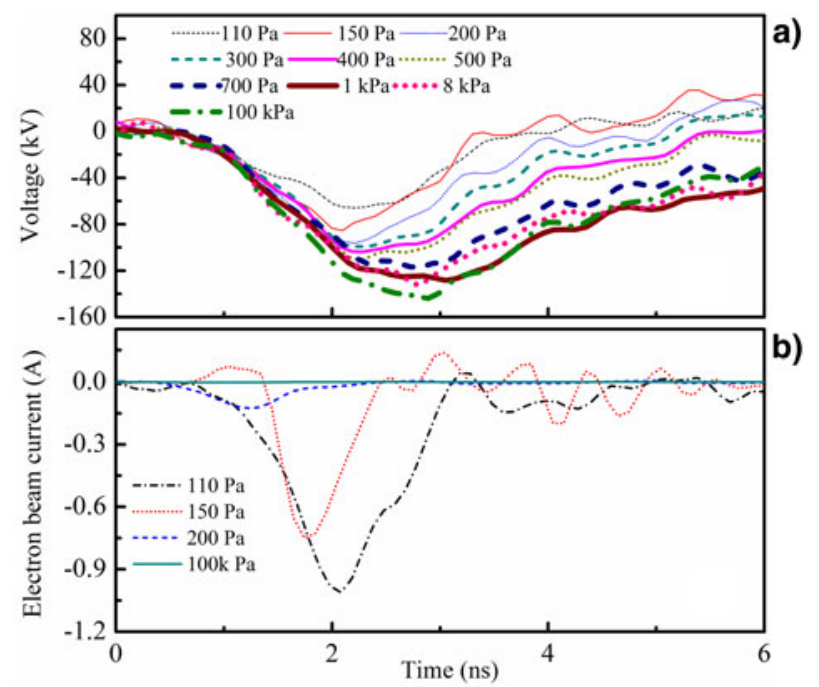

Fig. 12. (Color online) Waveforms of voltage pulses (a) and runaway electron beam current behind foil (b) at different pressures of SF 6 . VPG-30-200 generator, $d=12 \mathrm{~mm}$. 


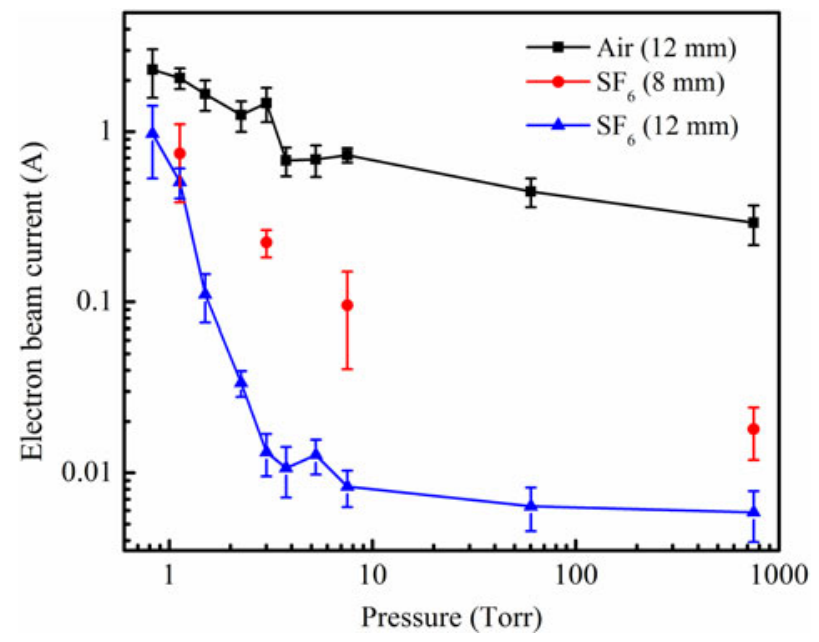

Fig. 13. (Color online) SAEB amplitude vs. pressures of $\mathrm{SF}_{6}$ and air at different gap spacing. VPG-30-200 generator, $d=12 \mathrm{~mm}$.

\section{SAEB PARAMETERS FOR $\mathrm{SF}_{6}$}

The conducted studies showed that the SAEB in $\mathrm{SF}_{6}$ had the following characteristics. First, the SAEB amplitude for $\mathrm{SF}_{6}$ was much lower (more than an order of magnitude) than that for air and nitrogen. The decrease of SAEB amplitude was mainly due to the much higher electron energy lost in the excitation and ionization in $\mathrm{SF}_{6}$ comparing with the electron loss in air and nitrogen. Furthermore, the effect of electron attachment on $\mathrm{SF}_{6}$ molecules was not strong. This followed from the fact that the SAEB amplitudes for air and nitrogen were almost the same (as known, air contains $21 \%$ of electronegative gas - oxygen) and that the SAEB amplitude for non-electronegative heavy gases (argon and krypton), was lower that for air and nitrogen.

Second, the diffuse discharge in $\mathrm{SF}_{6}$ was formed at both negative and positive polarities of the electrode with small curvature radius. In the case of positive polarity, SAEB from the gap was not detected, because the energies of RAEs here were too low. From our point of view, because of high efficiency of the characteristic radiation, the RAEs could participate in the formation of a diffuse discharge (Kozyrev et al., 2011).

Third, under the conditions of both positive and negative polarities, the breakdown of the gap was due to the ionization wave whose front crossed the gap. The ionization wave velocity in $\mathrm{SF}_{6}$ was lower than that in nitrogen and air. It explained the phenomenon that the SAEB width for $\mathrm{SF}_{6}$ was longer than that for air and nitrogen. Moreover, with a large discharge gap, the ionization wave velocity decreased with the increase of the pressures of $\mathrm{SF}_{6}$, leading to the increase of the SAEB width (Baksht et al., 2008).

Fourth, the energy of the main group of RAEs in $\mathrm{SF}_{6}$ was lower than that in air. Furthermore, the said energy in both gases $\left(\mathrm{SF}_{6}\right.$ and air) was lower than $e U_{\mathrm{m}}$.

\section{CONCLUSION}

From our studies, the following conclusions could be drawn:

- The SAEB amplitude for $\mathrm{SF}_{6}$ at pressures of $0.05-0.1 \mathrm{MPa}$ is much lower than that for air and nitrogen and is commensurable with the SAEB amplitude for krypton. This is due to the increase of electron energy which is lost in excitation and ionization in heavy gases. The attachment of electrons plays a small role in SAEB generation, resulting in almost the same SAEB amplitudes in air and nitrogen.

- At a pressure of $0.1 \mathrm{MPa}$ and the same voltage across the gap, the energy of RAEs generated in $\mathrm{SF}_{6}$ is lower than that in air.

- The diffuse discharge in $\mathrm{SF}_{6}$ and $\mathrm{SF}_{6}$-nitrogen mixture is formed not only at negative polarity but also at positive polarity of the electrode with small curvature radius.

- The obtained data confirm the generation mechanism of most of the RAEs between the ionization wave front and the plane anode. The SAEB width is substantially influenced by the ionization wave front velocity. The ionization wave velocity decreases with the increase of the pressure in $\mathrm{SF}_{6}$, nitrogen, and air. Comparing with the ionization wave velocity in air and nitrogen, the velocity is lower in $\mathrm{SF}_{6}$, so the SAEB width for $\mathrm{SF}_{6}$ is longer than that for air and nitrogen.

\section{ACKNOWLEDGEMENTS}

The work on the first setup was supported by RFBR under Grant \#12-08-00105-a. The work on the second setup was supported by the National Natural Science Foundation of China under Grants 51222701, 51207154, the National Basic Research Program of China under Grant 2014CB239505, the Chinese Academy of Sciences Visiting Professorship for Senior international scientists under Grant 2012T1G0021, and the State Key Laboratory of Alternate Electrical Power System with Renewable Energy Sources under Grant LAPS14009.

\section{REFERENCES}

Alekseev, S.B., OrlovskiI, V.M. \& Tarasenko, V.F. (2003). Electron beam formed in a diode filled with air or nitrogen at atmospheric pressure. Tech. Phys. Lett. 29, 411-413.

Alekseev, S.B., Lomaev, M.I., RybKa, D.V., Tarasenko, V.F., ShaO, T., Zhang, C. \& Yan, P. (2013). Generation of runaway electrons in atmospheric pressure air under $30-200 \mathrm{kV}$ voltage pulses of rise time $1.5 \mathrm{~ns}$. High Volt. Engine. 39, 2112-2118.

BABICH, L.P. \& LoIKO, T.V. (1985). Energy spectra and time parameters of the runaway electrons at a nanosecond breakdown in dense gases. Tech. Phys. 55, 956-958.

BABICH, L.P. \& LoIKo, T.V. (1991). Runaway electrons at high voltage nanosecond discharges in sulfur hexafluoride at pressure of 1 atm. Tech. Phys. 61, 153-155.

BABICH, L.P. (2003). High-energy phenomena in electric discharges in dense gases: Theory, experiment, and natural phenomena. In ISTC Science and Technology Series. Arlington, VA: Futurepast. 
BABICH, L.P. \& LoIKo, T.V. (2010). Peculiarities of detecting pulses of runaway electrons and X-rays generated by high-voltage nanosecond discharges in open atmosphere. Plasma Phys. Rep. 36, 263-270.

BaKsht, E.KH., Lomaev, M.I., RybKa, D.V. \& Tarasenko, V.F. (2006). High-current-density subnanosecond electron beams formed in a gas-filled diode at low pressures. Tech. Phys. Lett. 32, 948-950.

BaKsht, E.Kh., Burachenko, A.G., Erofeev, M.V., Lomaev, M.I., RybKa, D.V., Sorokin, D.A. \& TARASEnKo, V.F. (2008). Nanosecond discharge in sulfur hexafluoride and the generation of an ultrashort avalanche electron beam. Laser Phys. 18, 732-737.

Baksht, E.Kh., Burachenko, A.G., Kostyrya, I.D., Lomaev, M.I., RybKa, D.V., Shulepov, M.A. \& Tarasenko, V.F. (2009). Runaway-electron-preionized diffuse discharge at atmospheric pressure and its application. J. Phys. D: Appl. Phys. 42, 185201.

Baksht, E.Kh., Burachenko, A.G., Kozhevnikov, V.Y., Kozyrev, A.V., Kostyrya, I.D. \& Tarasenko, V.F. (2010). Spectrum of fast electrons in a subnanosecond breakdown of air-filled diodes at atmospheric pressure. J. Phys. D: Appl. Phys. 43, 305201.

BortnIK, I.M. (1998). The Physical properties and the electrical strength of sulfur hexafluoride. Moscow: Energoatomizdat.

Erofeev, M.V., Baksht, E.Kh., Tarasenko, V.F. \& Shut'Ko, Yu.V. (2013). Generation of runaway electrons in a nonuniform electric field by applying nanosecond voltage pulses with a frequency of 100-1000 Hz. Tech. Phys. 58, 200-206.

Gross, R.W.F. \& Bott, J.F. (eds). (1976). Handbook of Chemical Lasers. http://www.osti.gov/scitech/servlets/purl/7321405.

IvANOv, S.N. (2013). The transition of electrons to continuous acceleration mode at subnanosecond pulsed electric breakdown in high-pressure gases. J. Phys. D: Appl. Phys. 46, 285201.

Kostyrya, I.D., Baksht, E.Kh. \& Tarasenko, V.F. (2010). An efficient cathode for generating a super short avalanche electron beams in air at atmospheric pressure. Instr. Exper. Techn. 53, $545-548$.

Kostyrya, I.D., RybKa, D.V. \& TARasenko, V.F. (2012). The amplitude and current pulse duration of a supershort avalanche electron beam in air at atmospheric pressure. Instr. Exper. Techn. 55, 72-77.

Kostyrya, I.D., RybKa, D.V., Tarasenko, V.F., Kozyrev, A.V. \& BAKsht, E.KH. (2013). Occurrence of runaway electrons behind the cathode under subnanosecond breakdown of air at atmospheric pressure. Russ. Phys. J. 55, 1493-1496.

Kozyrev, A.V., Tarasenko, V.F., Baksht, E.Kh. \& Shut' Ko, Yu.V. (2011). Soft X-ray generation and its role in breakdown of air gap at elevated pressure. Tech. Phys. Lett. 37, 1054-1057.

Levko, D., Gurovich, V.Tz. \& KrasiK, Ya.E. (2012a). Conductivity of nanosecond discharges in nitrogen and sulfur hexafluoride studied by particle-in-cell simulations. J. Appl. Phys. 111, 123303.

LeVko, D., Krasik, Ya.E. \& Tarasenko, V.F. (2012b). Present status of runaway electron generation in pressurized gases during nanosecond discharges. Internat. Rev. Phys. 6, 165-195.

Mesyats, G.A., Korovin, S.D., Sharipov, K.A., Shpak, V.G., ShuNAILOV, S.A. \& YALANDIN, M.I. (2006). Dynamics of subnanosecond electron beam formation in gas-filled and vacuum diodes. Tech. Phys. Lett. 32, 18-22.

Mesyats, G.A., Reutova, A.G., Sharypov, K.A., Shpak, V.G., ShuNAILOv, S.A. \& Yalandin, M.I. (2011). On the observed energy of runaway electron beams in air. Laser Part. Beams 29, 425-435.

Shao, T., Tarasenko, V.F., Zhang, C., Baksht, E.Kh., Yan, P. \& SHUT'Ko, Yu.V. (2012a). Repetitive nanosecond-pulse discharge in a highly nonuniform electric field in atmospheric air: X-ray emission and runaway electron generation. Laser Part. Beams 30, 369-378.

Shao, T., Tarasenko, V.F., Zhang, C., Lomaev, M.I., Sorokin, D.A., Yan, P., Kozyrev, A.V. \& BAKSht, E.KH. (2012b). Spark discharge formation in an inhomogeneous electric field under conditions of runaway electron generation. J. Appl. Phys. 111, 023304

Shao, T., Tarasenko, V.F., Zhang, C., Burachenko, A.G., Rybka, D.V., Kostyrya, I.D., Lomaev, M.I., BaKsht, E.Kh. \& Yan, P. (2013). Application of dynamic displacement current for diagnostics of subnanosecond breakdowns in an inhomogeneous electric field. Rev. Sci. Instrum. 84, 053506.

TARASENKO, V.F. (2001). Efficiency of a nitrogen UV laser pumped by a self-sustained discharge. Quantum Electron. 31, 489-494.

Tarasenko, V.F., Orlovskit, V.M. \& Shunailov, S.A. (2003). Forming of an electron beam and a volume discharge in air at atmospheric pressure. Russ. Phys. J. 46, 325-327.

Tarasenko, V.F., Skakun, V.S., Kostyrya, I.D., Alekseev, S.B. \& OrLOVSKII, V.M. (2004). On formation of subnanosecond electron beams in air under atmospheric pressure. Laser Part. Beams 22, 75-82.

Tarasenko, V.F., Shpak, V.G., Shunailov, S.A. \& Kostyrya, I.D. (2005). Supershort electron beam from air filled diode at atmospheric pressure. Laser Part. Beams 23, 545-551.

TARASENKO, V.F. (2006). Nanosecond discharge in air at atmospheric pressure as an $\mathrm{X}$-ray source with high pulse repetition rates. Appl. Phys Lett. 88, 081501.

Tarasenko, V.F., Rybka, D.V., Baksht, E.Kh., Kostyrya, I.D. \& LOMAEv, M.I. (2007). On the generation of supershort avalanche electron beams and $\mathrm{x}$-radiation during nanosecond discharges in dense gases (result and discussion). Russ. Phys. J. 50, 944-954.

Tarasenko, V.F., Baksht, E.Kh., Burachenko, A.G., Kostyrya, I.D., Lomaev, M.I. \& RybKa, D.V. (2008a). Supershort avalanche electron beam generation in gases. Laser. Part. Beams 26, 605-617.

Tarasenko, V.F., RybKa, D.V., BaKsht, E.Kh., Kostyrya, I.D. \& LOMAEV, M.I. (2008b). Generation and measurement of subnanosecond electron beams in gas-filled diodes. Instr. Exper. Techn. 51, 213-219.

Tarasenko, V.F., BaKsht, E.Kh., Burachenko, A.G., Kostyrya, I.D., LoMAEV, M.I. \& RYBKA, D.V. (2008c). Generation of supershort avalanche electron beams and formation of diffuse discharges in different gases at high pressure. Plasma Dev. Oper. 16, 267-298.

Tarasenko, V.F., Baksht, E.Kh., Burachenko, A.G., Kostyrya, I.D., Lomaev, M.I. \& Sorokin, D.A. (2010). Modes of generation of runaway electron beams in $\mathrm{He}, \mathrm{H}_{2}, \mathrm{Ne}$ and $\mathrm{N}_{2}$ at a pressure of 1-760 Torr. IEEE Trans. Plasma Sci. 38, 2583-2587.

TARasenko, V.F. (2011). Parameters of a supershort avalanche electron beam generated in atmospheric-pressure air. Plasma Phys. Rep. 37, 409-421.

Tarasenko, V.F., Kostyrya, I.D., Baksht, E.Kh. \& RybKa, D.V. (2011). SLEP-150M compact supershort avalanche electron beam accelerator. IEEE Trans. Dielectr. Electr. Insul. 18, $1250-1255$. 
Tarasenko, V.F., Erofeev, M.V., Lomaev, M.I., Sorokin, D.A. \& RybKA, D.V. (2012a). Two-component structure of the current pulse of runaway electrons generated during electric breakdown of elevated-pressure nitrogen. Plasma Phys. Rep. 38, 922-929.

Tarasenko, V.F., Rybka, D.V., Burachenko, A.G., Lomaev, M.I. \& BALzovsky, E.V. (2012b). Measurement of extreme-short current pulse duration of runaway electron beam in atmospheric pressure air. Rev. Sci. Instrum. 83, 086106.

Tarasenko, V.F., Baksht, E.Kh., Burachenko, A.G., Kostyrya, I.D. \& RyвKA, D.V. (2013b). Energy of electrons generated during a subnanosecond breakdown in atmospheric-pressure air. Plasma Phys. Rep. 39, 592-599.

Tarasova, L.V., Khudyakova, L.N., Loiko, T.V. \& Tsukerman, V.A. (1974). The fast electrons and X-Ray radiation of nanosecond pulsed discharges in gases under 0, 1-760 Torr. J. Tech. Phys. 44, 564-568.
Yalandin, M.I. \& ShPaK, V.G. (2001). Compact high - power subnanosecond repetitive - pulse generators. Instr. Exper. Techn. 44, 285-310.

Zagulov, F.YA., Kotov, A.S., ShPaK, V.G., Yurike, Ya.YA. \& YALANDIN, M.I. (1989). RADAN-small-sized pulse-repetitive highcurrent accelerators of electrons. Prib. Tekh. Eksper. 23, 146-149 (in Russian).

Zhang, C., Shao, T., Yu, Y., Niu, Z., Yan, P. \& Zhou, Y. (2010). Detection of $\mathrm{x}$-ray emission in a nanosecond discharge in air at atmospheric pressure. Rev. Sci. Instrum. 81, 123501.

Zhang, C., Tarasenko, V.F., Shao, T., Baksht, E.K., Burachenko, A.G., Yan, P. \& Kostyray, I.D. (2013). Effect of cathode materials on the generation of runaway electron beams and $\mathrm{X}$-rays in atmospheric pressure air. Laser Part. Beams 31, 353-364. 